Polarized Electron Sources

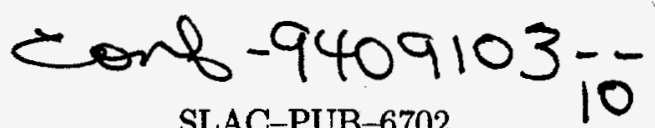

SLAC-PUB-6702

December 1994

(N)

\title{
REVIEW OF THE SLAC AND LES HOUCHES WORKSHOPS ${ }^{\star}$
}

\author{
Charles Y. Prescott \\ Stanford Linear Accelerator Center \\ Stanford University, Stanford CA 94309
}

I. Introduction. Polarized Electron Source workshops have been held at varying intervals, beginning in 1983 when Charles Sinclair convened the first at SLAC. Since that time, three workshops were held in conjunction with the International Spin Symposia and two at other occasions. The increasing importance of polarized electron beams at accelerators has stimulated interest in these workshops. Two workshops have been held since the last International Spin Symposium in Nagoya. In 1993, a workshop was held at SLAC, and in 1994 at Les Houches, a polarized electron beam session was held as part of a polarized beam and targets workshop. This report summarizes highlights from the latter two workshops.

\section{History of Polarized Electron Sources Workshops}

$\begin{array}{lll}\text { Year } & \text { Place } & \text { Convenor } \\ 1983 & \text { SLAC } & \text { C. Sinclair } \\ 1988 & \text { Minneapolis } & \text { C. Sinclair } \\ 1990 & \text { Bonn } & \text { E. Reichert } \\ 1992 & \text { Nagoya } & \text { T. Nakanishi } \\ 1993 & \text { SLAC } & \text { J. Clendenin (SLAC) } \\ & & \text { T. Maruyama (SLAC) } \\ 1994 & \text { D. Schultz (SLAC) } \\ & \text { Les Houches } & \text { M. Leduc (ENS Paris) } \\ & & \text { E. Steffen (MPI Heidelberg) }\end{array}$

The workshops have experienced a growing attendance. These workshops report on progress in all aspects of polarized electron beams and support the polarization progress at labs like SLAC, MIT-Bates, and Mainz, where experiments are running, and at labs such as CEBAF, NIKHEF, and KEK, where future experiments are likely to be run. Interest in polarized electrons for a future linear collider is strong. The frequency of one workshop per year should continue into the future as long as this interest in experiments with polarized electron beams remains strong.

II. The SLAC Workshop on Photocathodes for Polarized ElectronSources for Accelerators (September 8-10, 1993). This workshop was organized by J. Clendenin, T. Maruyama, and D. Schultz, and supported by SLAC. The focus of this workshop was on photocathodes for use in polarized electron sources at accelerators. The reports presented in this workshop have been combined into a proceedings consisting of copies of transparencies from each talk [1]. The workshop contributions can be divided into two categories, accelerators and cathode studies. Listed below are the laboratories and institutions represented, the speakers, and their topics. The workshop had 43 participants representing 22 institutions and laboratories

* Work supported by Department of Energy contract DE-AC03-76SF00515.

Invited talk presented at the 11th International Symposium on Spin Physics and the 8th International Symposium on Polarization Phenomena in Nuclear Physics, Bloomington, Indiana, September 15-22, 1994

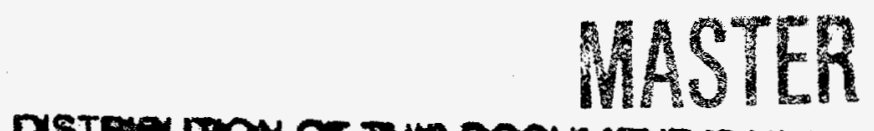




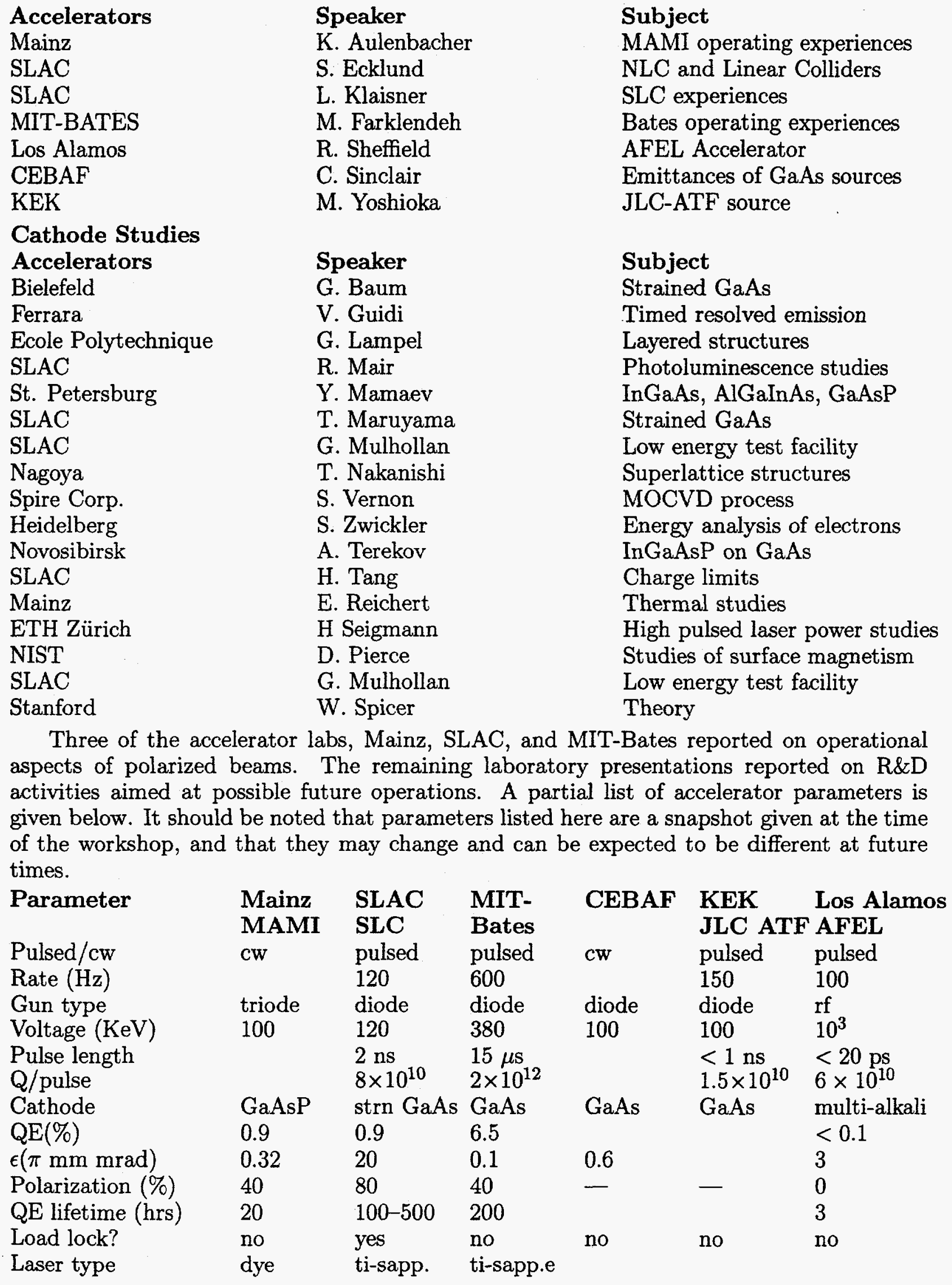




\section{DISCLAIMER}

This report was prepared as an account of work sponsored by an agency of the United States Government. Neither the United States Government nor any agency thereof, nor any of their employees, makes any warranty, express or implied, or assumes any legal liability or responsibility for the accuracy, completeness, or usefulness of any information, apparatus, product, or process disclosed, or represents that its use would not infringe privately owned rights. Reference herein to any specific commercial product, process, or service by trade name, trademark, manufacturer, or otherwise does not necessarily constitute or imply its endorsement, recommendation, or favoring by the United States Government or any agency thereof. The views and opinions of authors expressed herein do not necessarily state or reflect those of the United States Government or any agency thereof. 


\section{DISCLAIMER}

Portions of this document may be illegible in electronic image products. Images are produced from the best available original document. 
III. The Les Houches Workshop on Polarized Beams and Targets; Sensitive Tools for the Study of Solids, Nuclei, and Particles (June 7-10, 1994). This Scientific Network on "Polarized Beams and Targets" workshop was organized under the auspices of the European Community "Human Capital and Mobility." The organizers were Michele Leduc (ENS Paris) and Erhard Steffens (MPI Heidelberg). Sixty three participants representing 36 institutions attended the workshop.

One day-long session was devoted to polarized electron sources and semiconductor photocathodes. Other topics at the workshop included lasers, optical pumping of gas targets, ${ }^{3} \mathrm{He}$ targets, and selected topics in polarized neutrons and atomic physics.

The talks covering the electron sources and semiconductor photocathodes were combined into one day and summarized in one evening session. Below are listed the presentations from those sessions relating to electron sources and photocathodes.

The talks are summarized in a collection of abstracts available from the organizers [2].

$\begin{array}{ll}\begin{array}{l}\text { Institution } \\ \text { Palaiseau }\end{array} & \begin{array}{l}\text { Speaker } \\ \text { G. Lampel }\end{array} \\ \text { ETH Zürich } & \text { F. Meier } \\ \text { SLAC } & \begin{array}{l}\text { G. Mulhollan } \\ \text { Mainz }\end{array} \\ \text { Sainz } & \text { H. Fischer } \\ \text { Palaiseau } & \text { D. M. Campbell } \\ \text { Orsay } & \text { S. Essabaa }\end{array}$

IV. Summary. Gallium arsenide cathodes and layered structures of strained gallium arsenide and gallium arsenide superlattices have been shown to provide high polarization and high currents in photoemission by polarized laser beams. At accelerator facilities with running experiments, these sources have proven to operate with high reliability. Pulsed currents of up to 10 amps in 2 nanoseconds have been used at SLAC for the SLC. Polarizations up to $85 \%$ have been achieved for experiments. Mainz has operated photoemission sources with continuous currents, but in some conditions, the cathodes have shown a loss of quantum efficiency at the spot where the laser hits the photocathode when steady currents in excess of $150 \mu \mathrm{A}$ are drawn. Advances in laser technology, vacuum technology and cathodes materials continue to make the electron source devices better and easier to fabricate and use.

Helium afterglow sources at Rice University and Orsay offer an alternative to photoemission sources for high average currents $(\geq 100 \mu \mathrm{A})$ with polarization in the range of $60-80 \%$.

1. Proceedings of the Workshop on Photocathodes for Polarized Electron Sources for Accelerators, organized by J. Clendenin et al., SLAC-432 (1993).

2. Abstracts of the Workshop on Polarized Beams and Targets; Sensitive Tools for the Study of Solids Nuclei, and Particles, organized by M. Leduc (ENS Paris) and E. Steffens (MPI Heidelberg), Les Houches (1994). 